\title{
Modifying attitudes about modified foods: increased knowledge leads to more positive attitudes
}

Article

Accepted Version

Creative Commons: Attribution-Noncommercial-No Derivative Works 4.0

McPhetres, J., Rutjens, B. T., Weinstein, N. ORCID: https://orcid.org/0000-0003-2200-6617 and Brisson, J. A. (2019) Modifying attitudes about modified foods: increased knowledge leads to more positive attitudes. Journal of Environmental Psychology, 64. pp. 21-29. ISSN 0272-4944 doi: https://doi.org/10.1016/j.jenvp.2019.04.012 Available at https://centaur.reading.ac.uk/93588/

It is advisable to refer to the publisher's version if you intend to cite from the work. See Guidance on citing.

Published version at: http://dx.doi.org/10.1016/j.jenvp.2019.04.012

To link to this article DOI: http://dx.doi.org/10.1016/j.jenvp.2019.04.012

Publisher: Elsevier

All outputs in CentAUR are protected by Intellectual Property Rights law, including copyright law. Copyright and IPR is retained by the creators or other copyright holders. Terms and conditions for use of this material are defined in the End User Agreement. 


\section{CentAUR}

Central Archive at the University of Reading

Reading's research outputs online 
Modifying attitudes about modified foods: increased knowledge leads to more positive attitudes

\author{
Jonathon McPhetres ${ }^{1 *}$ \\ Bastiaan T. Rutjens ${ }^{2}$ \\ Netta Weinstein ${ }^{3}$ \\ Jennifer A. Brisson ${ }^{4}$
}

*This is the preprint version of a manuscript in-press at Journal of Environmental Psychology.*

${ }^{*}$ Corresponding author. Email: jon.mcphetres@gmail.com

${ }^{1}$ Clinical and Social Sciences in Psychology, University of Rochester, Rochester, NY, USA

${ }^{2}$ Department of Psychology, University of Amsterdam, Amsterdam, The Netherlands.

${ }^{3}$ School of Psychology, Cardiff University, Cardiff, UK

${ }^{4}$ Department of Biology, University of Rochester, Rochester, NY, USA 


\begin{abstract}
Genetically modified (GM) foods are often met with harsh public opposition, though little research has attempted to understand why this is. The research that does exist has focused on identifying the role of immutable beliefs, such as morality and politics, which are difficult to change. Therefore, research may benefit from identifying mutable predictors of science rejection - predictors which can be modified through interventions-so efforts can be made to increase public support for scientific advancements. Here we present four studies in which we investigate a lack of domain-specific science literacy - literacy of GM technology - as a strong and unique predictor of GM food skepticism. Results from Studies 1 and 2 demonstrated that knowledge of GM technology is a unique predictor of GM food attitudes above general science knowledge and demographic controls. Study 3 (preregistered) demonstrates that the unique predictive value of GM-specific knowledge replicates in the US, the UK, and the Netherlands. In Study 4, we sought to overcome this lack of knowledge by teaching people the basic science behind GM technology using a five-week, longitudinal experimental design. Results showed that learning about the science behind GM technology leads to more positive explicit attitudes towards GM foods, greater willingness to eat GM products, and lowered perceptions of GM foods as risky. Thus, the present results provide some support for the deficit model of science attitudes within the context of GM foods. These results also provide a relatively simple mold for future interventions to overcome GM skepticism, suggesting that researchers and scientists may wish to focus on communicating the basic science behind GM technology and increasing science literacy.
\end{abstract}

Keywords: GMO, GM foods, science education, deficit model, attitudes. 
Modifying attitudes about modified foods: increased knowledge leads to more positive attitudes

Since their introduction to the commercial market in the 1990s, genetically modified (GM) foods have received vitriolic opposition from the public based on concerns about possible environmental and health risks. Several campaigns have sought to mandate the labeling of GM foods in the US (Charles, 2014; Mayer, 2015; Nep \& O’Doherty, 2013), and GM foods are already highly regulated in many European markets (e.g., Devos et al, 2006; Frewer, van der Lans, Fischer, Reinders, Menozzi, Zhang...\& Zimmerman, 2013). In stark contrast to public skepticism, the majority of US scientists are favorable towards GM foods and a recent report from the National Academy of Sciences (2016) reviewing a wide range of published research found no convincing evidence for negative health or environmental effects of GM foods. Attitudes towards GM foods divides the public from scientists more than any other topic, including widely divisive ones such as climate change or vaccinations (Pew Research Center, 2016). However, little research addresses the reasons for this gap between scientific knowledge and public attitudes, despite the importance of communicating robust scientific findings to shape public behavior.

Empirically, several key benefits of GM foods have been identified, including the ability to grow larger amounts of crops in harsh environments and without the use of pesticides (National Academy of Sciences, 2016; Wesseler \& Zilberman, 2014), the ability to protect produce from disease and extinction and to increase the nutritional value of crops (Harmon, 2013; Sharma, Kaur, \& Singh, 2017), and the importance of GM organisms in medical applications (e.g., insulin production). However, identifying these or other benefits is nonconsequential if the public is unwilling to consider the scientific evidence or if they do not give 
weight to scientific consensus. If the goal is to promote support for the latest scientific advancements, then an important first step is to identify the factors underlying GM skepticism, to guide further efforts for increasing support.

The reasons for GM food skepticism are likely diverse. One source of skepticism may be incorrect intuitions about how the world works. For example, a reliance on intuitive conceptions about the natural world may make biotechnology difficult to understand (Blancke, Van Breusegem, De Jaeger, Brackmen, \& Van Montagu, 2015), folk-beliefs about genetic essentialism (Dar-Nimrod \& Heine, 2011; Heine, 2017) may lead to aversion towards GM technology, and intuitive preferences for "naturalness" (Kronberger, Wagner, \& Nagata, 2014; Rozin, Fischler, Shields-Argel'es, 2009; Scott \& Rozin, 2017) may make GM foods seem less safe and less attractive. Further, GM techniques are complex and difficult to understand without advanced scientific training. One survey found that 54\% of Americans "know very little or nothing at all" about GM foods (Hallman, Cuite, \& Morin, 2013) and this lack of knowledge may be one factor contributing to skepticism.

Supporting the idea that a lack of scientific information drives negative attitudes towards science (e.g., the information deficit model; Bak, 2001; Miller, 1983; Wynne, 1982), some research has examined the role of general and specific knowledge in attitudes about science topics. For example, one recent exploratory study suggests that general science knowledge may be a strong predictor of attitudes towards GM foods but not other topics (Rutjens, Sutton, \& van der Lee, 2018). In another study, meta-analytic findings (Allum, Sturgis, Tabourazi \& BruntonSmith, 2008) indicate a small, positive correlation between science knowledge and general science attitudes. However, general knowledge was not important specifically for GM foods; instead, knowledge about biology and biotechnology are of more importance for determining 
attitudes towards biotechnology and climate change. Following this, other recent studies have suggested that knowledge specific to GM technology may be more important for GM attitudes. For example, negative GM attitudes are strongest in those with the least knowledge (Fernbach, Light, Scott, Inbar \& Rozin, 2019). Other research has shown that knowledge about risk-related aspects of GM technology are the better predictors of attitudes (Cuite, Aquino, \& Hallman, 2005).

Although most research conducted has presented cross-sectional and correlational evidence linking science knowledge to GM food attitudes, some research has attempted to communicate information about GM foods in order to change attitudes (Frewer, Howard, \& Shepherd, 1998; Frewer, Scholderer, \& Bredahl, 2003). However, rather than communicating basic scientific information about the science behind GM technology, these studies focused on communicating that GM foods are low in risk or on listing the benefits of GM food production. The approach ultimately resulted in more polarized attitudes towards GM foods and were thus interpreted as evidence against the deficit model. If efforts are to be made to change attitudes by communicating scientific information, this information should be presented in a neutral fashion which avoids confronting people with new, disagreeable opinions or facts which threaten preexisting beliefs and convictions.

In the present studies, we examined the extent that teaching people about the science behind GM procedures and foods leads to more positive attitudes towards GM foods. First, we expected that specific knowledge about GM procedures and foods would be uniquely related to attitudes towards GM foods - that is, knowledge would relate above and beyond general science knowledge and demographic factors. Second, we expected that teaching people about the science behind GM foods would lead to more positive attitudes towards GM foods, lowered risk 
perceptions, and a greater willingness to eat GM foods. We first tested these hypotheses by looking at the relation between general science knowledge, GM-specific knowledge, and GM attitudes using cross-sectional data (Studies 1 and 2). We then examined whether this relation replicated across three countries: The US, the UK, and The Netherlands (Study 3). We then tested the extent that GM-specific knowledge predicts GM attitudes over and above general science knowledge and demographic controls. Finally, we conducted a longitudinal experiment (Study 4), to examine whether teaching people about the science behind GM foods leads to more positive explicit attitudes, lowered risk perceptions, and a greater willingness to eat GM foods.

\section{Study 1}

\section{Participants}

Data were obtained from the General Social Survey 2006 cohort (Smith, Marsden, Hout, \& Kim, 2017). A total of 778 individuals (351 male) responded to the relevant question set. Participants were $76 \%$ white, $16 \%$ black, $9 \%$ other, with an average age of 46.43 years $(S D=$ $16.84)$, and an average of 13.86 years of education $(S D=2.86)$.

\section{Materials and Procedure}

GM Foods. The main dependent variable was whether participants reported they would eat GM foods, and they responded on a scale of 1 (don't care if foods have been genetically modified), 2 (willing to eat, but prefer unmodified foods), and 3 (will not eat genetically modified foods) and this item was reverse-coded so that a higher score indicates more willingness to eat.

Science knowledge. Participants responded to 11 true/false questions about general science facts. These questions are displayed in Table 1 . The correct responses were summed into a science knowledge score ranging from 0 to 11 . 
Table 1. Science knowledge questions used in Studies 1 and 2.

Study 1.

1. It is the father's gene that decides whether the baby is a boy or a girl.

2. Electrons are smaller than atoms.

3. The center of the earth is very hot.

4. Lasers work by focusing sound waves.

5. All radioactivity is man-made

6. Antibiotics kill viruses as well as bacteria

7. The universe began with a huge explosion.

8. Human beings, as we know them today, evolved from earlier species of animals.

9. The continents on which we live have been moving their locations for millions of

9. years and will continue to move in the future.

10a. Does the Earth go around the Sun, or does the Sun go around the Earth?

$10 \mathrm{~b}$. How long does it take for the earth to go around the sun?

Study 2.

11. Nuclear plants destroy the ozone layer.

12. More than half of human genes are identical to those of mice.

13. Ordinary tomatoes, the ones we normally eat, do not have genes whereas genetically

13. modified tomatoes do.

14. For the first time in recorded history, some species of plants and animals are dying out

and becoming extinct.

15. Which travels faster: light or sound?

16. The earliest humans lived at the same time as the dinosaurs.

17. The primary human activity that causes global warming is the burning of fossil fuels such as coal and oil.

Note: $10 \mathrm{~b}$ was only displayed if $10 \mathrm{a}$ was answered correctly.

Control variables. Participants responded to several demographics questions.

Participants indicated their political views on a scale from 1 (extremely liberal) to 7 (extremely

conservative). We controlled for age, education (in years), household income (from $1=$ under

$\$ 1,000$ to $25=$ over $\$ 150,000$ ), sex ( 1 is male, 2 is female), race (two dummy code variables

created for Whites and African Americans), and region of the country (South versus the rest).

\section{Results}

A small but significant relation between general science knowledge and willingness to eat

GM foods was in evidence $(\beta=.12, p=.004$, partial $r=.11,95 \% \mathrm{CI}: .039, .199)$ above and beyond variance accounted for by control variables (age, education, sex, income, race, US 
region, and political orientation). The model (see Table S1) accounted for approximately $8 \%$ of the variance in willingness to eat GM foods (adjusted $R^{2}=.08, F(9,768)=8.54, p<.001$ ).

The above findings lent mild support to our hypothesis that a lack of science knowledge may underlie GM foods skepticism. However, these data do not allow us to investigate if knowledge specific to GM technology is a strong or unique predictor of GM food attitudes. While general science knowledge may be important, it only accounts for a small portion of variance in attitudes. Domain-specific knowledge about genetics may be more relevant and easier to target and may account for a larger portion of variance in attitudes. Given the broad results in Study 1, our goal in Study 2 was to identify the unique predictive values of GMspecific knowledge and general science knowledge, as well as to extend the findings of the previous study using a contemporary sample.

\section{Study 2}

\section{Participants}

We recruited 747 U.S. participants from university undergraduates $(n=262)$ and through the Research Match health survey recruitment system $(n=485)$. For simplicity, we aggregate these data here, though results did not differ when the samples were analyzed individually. The survey was titled "Opinions about health topics." We excluded 66 participants for failing at least one attention check question (e.g. select agree and continue on; Maniacci \& Rogge, 2014). An additional four were excluded for not responding to all demographics items, resulting in a final sample of 677 individuals (507 female). The sample had an average age of 41.22 years $(S D=$ 19.69 ) and was $78 \%$ white, $13 \%$ Asian, $3 \%$ black, $3 \%$ Hispanic, and $3 \%$ other. Twenty percent of participants reported having earned a bachelor's degree and $28 \%$ earned an advanced degree. 
A sensitivity analysis indicates this sample size is large enough to detect effects as small as $r^{2}=$ .01 with $80 \%$ power.

\section{Materials and Procedure}

GM Attitudes and Knowledge. Participants responded to an 11-item scale $(\alpha=.96)$ measuring attitudes towards GM foods (e.g., It does not really matter to me whether the food I buy has been genetically modified; see Table S2), which was the main dependent variable. Next, participants answered 14 questions $(M=5.57, S D=2.84)$ regarding their knowledge of genetically modified foods (e.g., What effect does eating genetically modified foods have on your own genes?), which was the main independent variable (see supplementary materials). The questions were adapted from various online and academic sources (e.g. https://ag.purdue.edu/gmos/Pages/The-Science-of-GMOs.aspx) and were selected through pilot testing with an independent student sample. This quiz was designed to include a range of information about the science, methods, regulations, and benefits of GM foods and GM procedures. In contrast, past research has focused heavily on the risks and benefits of GM foods (e.g. Frewer et al., 1999).

General Science Knowledge. To compare the predictive value of GM-specific knowledge to general science knowledge, we included a scale measuring general science knowledge as a separate independent variable. The general science knowledge scale included the same 11 questions used in Study 1 as well as seven additional questions (Miller, 1998), resulting in a total of 18 items (see Table 1).

Control variables. For control variables, participants responded to measures of the preference for eating natural foods $(\alpha=.91)$ and preference for healthy foods $(\alpha=.87$; Lockie, Lyons, Lawrence, \& Mummery, 2002), which suppressed each other (see supplementary 
materials). So, we included only preference for natural foods because we felt it was more conservative and more important for GM attitudes. Also included were belief in genetic essentialism ( $\alpha=.84$; Bastian \& Haslam, 2006), and analytic thinking ability (Toplak, Stanovich \& West, 2014). These were included as possible alternative explanations of attitudes towards GM foods.

Participants also responded to demographics questions, which included three items measuring political orientation in social and economic issues and party preference $(\alpha=.90)$, ranging from 1 (extremely liberal) to 7 (extremely conservative). The six-item religiosity scale ( $\alpha$ $=.96$; Sharif, Cohen, \& Norenzayan, 2008) was scored so that higher scores indicated stronger religiosity. Two questions were also included regarding each parent's level of education $(\alpha=$ .79). Finally, participants were asked to rate their economic status and quality of life on a scale from 1 (worse than others) to 10 (much better than others), with the mid-point being "about average." This question was asked twice, one referring to childhood and the other referring to their current status; these two items were kept separate.

\section{Results}

Findings indicated GM knowledge was a strong and unique predictor of GM food attitudes (see Table 2) above control variables. We regressed the GM food attitudes score onto the GM knowledge score, the general science knowledge score, the 12 control items, and data source (i.e., undergraduates vs. Research Match). Overall, the model explained about 54\% of variance in GM food attitudes, (adjusted $\left.R^{2}=.538, F(19,657)=42.50, p<.001\right)$. Zero-order correlations are displayed in Table S3.

These results suggest that specific knowledge about GM foods and procedures is independent from one's general science knowledge and accounts for nearly twice the variance, as 
indicated by the partial correlations shown in Table 2, below. Additionally, knowledge about

GM foods uniquely predicts GM food attitudes, while controlling for one's general desire to eat natural foods, suggesting that these two concepts contribute to attitudes independently.

Table 2. Regression coefficients for GM-specific knowledge predicting GM Food Attitudes above general science knowledge and demographic variables (Study 2).

\begin{tabular}{lcrrrrr}
\hline \multicolumn{1}{c}{ Predictor } & $\boldsymbol{\beta}$ & \multicolumn{2}{c}{$\mathbf{9 5 \%} \mathbf{C I}$} & $\boldsymbol{t}$ & $\boldsymbol{p}$ & \multicolumn{1}{c}{ Partial $\boldsymbol{r}$} \\
\hline Source & .04 & -.067 & .151 & .75 & .451 & .03 \\
Age & .01 & -.085 & .095 & .12 & .909 & .00 \\
Female & -.05 & -.109 & .003 & -1.86 & .063 & -.07 \\
Other gender & .02 & -.029 & .077 & .89 & .376 & .04 \\
Education & .02 & -.061 & .101 & .49 & .626 & .02 \\
Parent's education & .03 & -.024 & .093 & 1.15 & .249 & .05 \\
Current socioeconomic status & .03 & -.025 & .087 & 1.08 & .281 & .04 \\
Childhood socioeconomic status & .04 & -.012 & .099 & 1.54 & .124 & .06 \\
Mixed & .00 & -.052 & .054 & .05 & .964 & .00 \\
Black & -.01 & -.061 & .046 & -.27 & .784 & -.01 \\
Hispanic & .01 & -.047 & .063 & .28 & .782 & .01 \\
Asian & .00 & -.060 & .064 & .06 & .950 & .00 \\
Political orientation & .01 & -.056 & .068 & .19 & .849 & .01 \\
Preference for natural foods & -.50 & -.557 & -.446 & -17.79 & $<.001$ & -.57 \\
Genetic essentialism & .07 & .014 & .119 & 2.50 & .013 & .10 \\
Religiosity & -.16 & -.223 & -.102 & -5.27 & $<.001$ & -.20 \\
Analytic thinking & .02 & -.037 & .086 & .78 & .435 & .03 \\
General science knowledge & .14 & .070 & .210 & 3.94 & $<.001$ & .15 \\
GM-specific Knowledge & .22 & .160 & .283 & 7.09 & $<.001$ & .27 \\
\hline
\end{tabular}

Note: $N=677$; standardized regression coefficients are displayed; all variables were entered simultaneously and interpreted in line with this analytic approach; for gender, male serves as the reference group; for race, white serves as the reference group.

\section{Study 3}

Study 2 highlighted the importance of domain-specific GM knowledge in relation to attitudes, but sampled from US samples only, who may have a different relationship with GM knowledge as compared to individuals from other, for example European, countries. Study 3 was therefore conducted as a multiple-country replication of Study 2, following the same procedures and using the same materials as Study 2. Sample size was estimated based on underestimating the effects observed in Study 2: to observe effects as small as $r^{2}=.07$, at least 107 subjects are 
needed from each sample. The sample sizes, hypotheses, and analysis plans were preregistered prior to data collection: https://osf.io/v8zag/?view_only=3068aec3d0d44d5a9e2dec0 0 cc01552ac.

\section{Participants and Procedure}

Participants. Data from the U.S. were collected via the Prolific recruitment website. Subjects were 362 adults (142 female) with an average age of 33.53 years $(S D=10.88)$. Subjects were primarily white (78\%); $33 \%$ had a bachelor's degree, $27 \%$ had some college, $20 \%$ had an advanced degree, and $11 \%$ had a high school education or less. Fifty-four subjects were excluded for failing at least one attention check or for not completing the main measures, resulting in a final sample of $n=309$.

Data from the Netherlands were collected using undergraduate subjects. Subjects were 155 students (124 female) with an average age of 20.12 years $(S D=3.57)$ and were primarily white $(72 \%)$. Eleven students were excluded for failing at least one attention check, nine did not complete any measures, and one who identified as 'other' gender was also excluded because this makes too small of a reference group, resulting in a final sample of $n=134$.

Data from the U.K. were also collected using undergraduate subjects. Subjects were 323 students (290 female) with an average age of 19.08 years $(S D=1.69)$ and were primarily white (85\%). Twenty-nine students were excluded for failing at least one attention check, for skipping demographics; one individual who identified as 'other' gender was also excluded resulting in a final sample of 293.

Materials. The materials and procedure were identical to those in Study 2. All study materials were presented in English. Details of the scales are presented in the supplementary materials. 


\section{Results}

For each country, we conducted the same multiple regression as in Study 2. Coefficients are presented in Table 3 below. In sum, GM-specific knowledge was a strong and unique predictor of GM attitudes for each country when controlling for other likely influences of attitudes (see supplementary materials for comparisons of attitudes and knowledge across countries). All three models explained a large amount of variance in GM attitudes: The Netherlands, adjusted $R^{2}=.461, F(16,117)=8.12, p<.001$; the UK: adjusted $R^{2}=.334, F(16$, $276)=10.14, p<.001$; the US: adjusted $R^{2}=.579, F(17,291)=25.89, p<.001$. These results add further evidence to our hypothesis that one's knowledge about GM foods is the better predictor of their attitudes. This predictor holds across three different countries, suggesting that GM-specific knowledge has a robust and generalizable association with GM attitudes. 


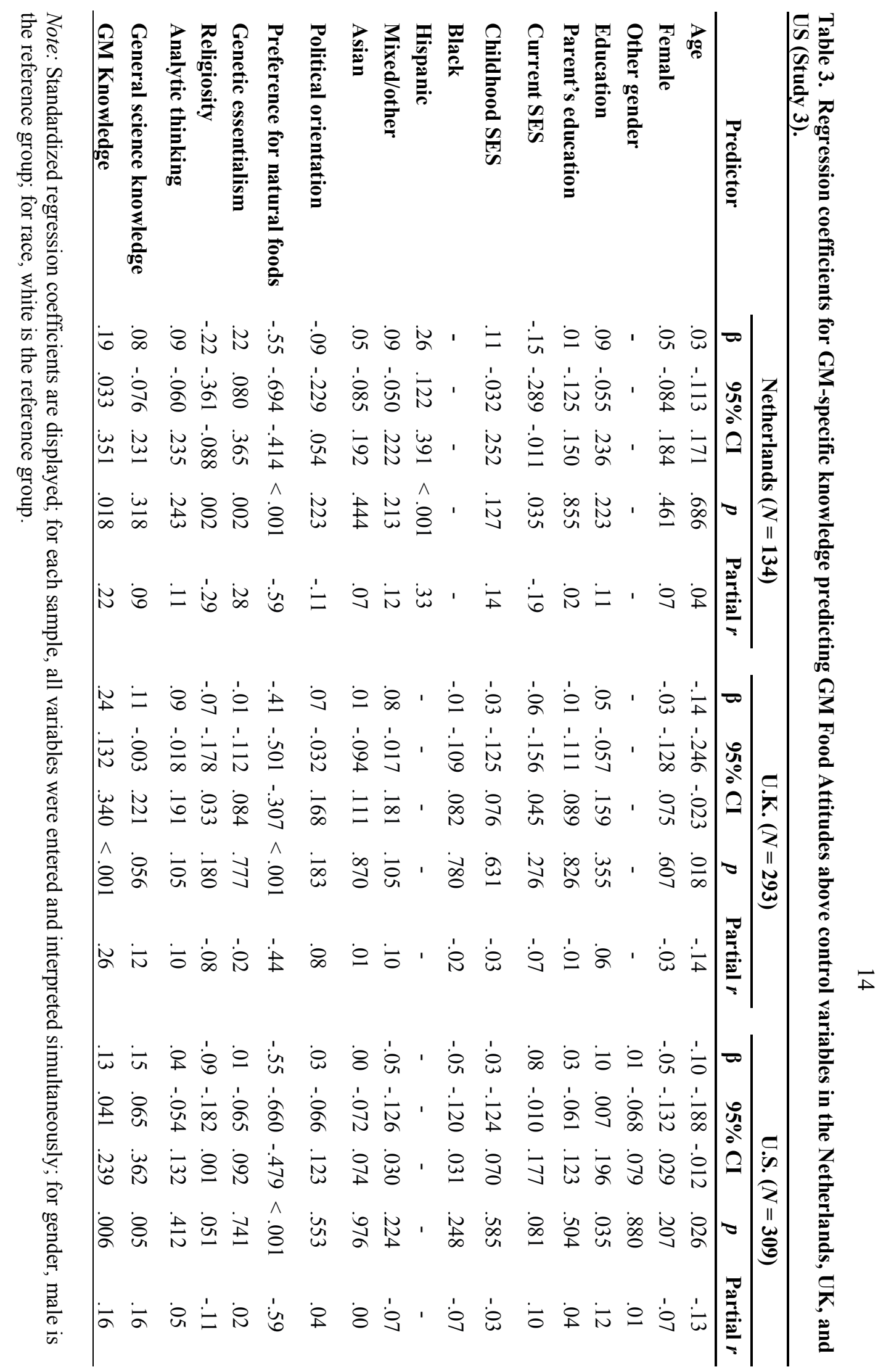




\section{Study 4}

The previous studies were correlational but were designed as a foundation for understanding how to change attitudes; thus, a final study used an experimental design to inform a causal understanding of the relation between GM-specific knowledge and GM attitudes. Thus, Study 4 involved a longitudinal, five-part online survey in which participants completed surveys weekly for five weeks. Though the study was not preregistered, the procedures and analysis plan were determined a priori. There were no deviations from this plan and no measures, conditions, or analyses have been excluded.

\section{Participants}

We recruited 231 US undergraduates in exchange for extra course credit. The study was titled "Online learning and attitudes processes" and was described as a study on learning and retention of scientific topics. Participants were 164 females, 65 males (2 identified as other), $45 \%$ white, $27 \%$ Asian, 13\% Latino, 9\% mixed/other, and 6\% black. The average age was 20.26 years $(S D=1.60)$ and, though participants were undergraduates, $9 \%$ reported having earned a 4 year degree. A sensitivity analysis indicates this sample size is large enough to detect between $\mathrm{X}$ within-subjects interactions as small as $\eta^{2} \mathrm{p}=.01$ with $80 \%$ power.

Attrition was modest: $86 \%$ completed Week 2, 85\% completed Week 3, 82\% completed Week 4 , and $77 \%$ completed Week 5 . The number of weeks completed was unrelated to any of the relevant outcome variables (see Tables S4-S6 for zero-order correlations).

\section{Materials and Procedure}

For Weeks 1 and 5, participants completed pre-and post-experiment measures of GM attitudes (as: .93, .95), GM knowledge, and general science knowledge measures (the same as used in Studies 2 and 3), as well as a four-item measure of perceiving GM foods as risky (e.g., I 
believe genetically engineered foods have already damaged the environment; as: .82, .86) and an implicit association test measuring GM versus organic foods as pleasant or unpleasant for a behavioral complement to self-report measures (Spence \& Townsend, 2006). The implicit association task included here was developed and scored using IATgen online software (Carpenter et al., 2018) and according to standard algorithm recommendations (Greenwald, Nosek \& Banaji, 2003).

For Weeks 2-4, participants were randomly assigned to one of two conditions (GM vs. Control) where they completed simple online learning modules created on the Qualtrics survey platform. In the GM condition, participants learned about the science behind genetics, DNA, and modification procedures. The information was selected by the first and fourth authors based on freely available information from Youtube and various science websites. Selection was based on the meeting the following criteria. First, the information was value-neutral and did not claim that GM foods were safe or unsafe (based on previous research that showed doing so had counterproductive effects). Second, the videos encouraged readers to make their own decisions about the information provided. Third, given the previous two constraints, the information was geared towards answering the questions in the quiz.

In the Control condition, participants learned about the science behind nutrition and healthy eating, metabolism, and how the body processes calories, fats, and vitamins. This condition was roughly matched for content (e.g. if one condition watched a video and saw an infographic, the other did as well) and the content was stylistically similar. For both conditions, each of the five weekly surveys took approximately 20 minutes to complete and ended by describing a different GM food item (see Table S7) and asking participants to rate how willing they would be to eat that item. 
Finally, we included four exploratory questions at Week 5; these were deemed exploratory because they are self-report and expected to be face valid. These are described in the supplementary materials (see Table S9). We also included two measures for purposes not related to the current investigation: one is a scale under development by the first author and is not discussed further. The other is a scale of autonomous and controlled orientation modified from (William \& Deci, 1996; see supplementary materials for correlations).

\section{Results}

Findings supported our main hypothesis that those who learned more about GM technology reported more positive GM food attitudes at Week 5 compared to Week 1. Evidence for this comes from a mixed-ANOVA using Week (pre vs. post at Weeks 1 and 5) as the withinsubjects factor and Condition (Control vs. GM) as the between-subjects factor. This analysis held constant correctly answered attention check questions in this model (which also accounted for the number of weeks completed), though a model not defining this covariate resulted in results of the same magnitude and pattern of significance (see supplementary materials). Zero-order correlations are shown in Tables S4-6.

As shown in Table 4 and Figure 1, the Condition X Week interaction was significant for GM attitudes, GM risk perception, and GM knowledge, but not for implicit attitudes. The main effect of Week (within-subjects changes) was non-significant for all variables (all $p \mathrm{~s}>.168$ ). The main effect of condition was significant only for GM knowledge $\left(p=.030, \eta^{2}{ }_{\mathrm{p}}=.03\right)$, indicating that those in the GM condition had higher knowledge scores, but this main effect was qualified by the predicted interaction. 
Table 4. Statistics and significance values for Condition X Week interactions in Study 4.

\begin{tabular}{lcccc}
\multicolumn{1}{c}{ Condition X Week Interaction } & $\boldsymbol{F}$ & $\boldsymbol{d} \boldsymbol{f}$ & $\boldsymbol{p}$ & $\boldsymbol{\eta}^{\mathbf{2}} \mathbf{p}$ \\
\hline GM Attitudes & 14.98 & 1,157 & $<.001$ & .09 \\
GM Risk Perception & 12.58 & 1,157 & .001 & .07 \\
GM Knowledge & 14.63 & 1,157 & .024 & .03 \\
Implicit Attitudes & 00.15 & 1,157 & .702 & $<.01$ \\
\hline
\end{tabular}

Note: $N=160$.

Support for the hypothesis that learning about GM foods increased positive attitudes was also reflected in an analysis of simple effects. No variables differed between conditions at Week 1, but all three variables differed at Week 5. Positive GM attitudes $(p=.010, d=-.41)$ and GM knowledge ( $p=.002, d=-.51)$ were significantly higher in the GM condition compared to the control condition, and GM foods were perceived as less risky in the GM condition ( $p=.026, d=$ $.35)$.

All of the within-subjects change occurred in the GM condition: from Week 1 to Week 5, GM attitudes and GM knowledge increased, and perception of GM risk decreased. The effects can be seen in Figure 1. No change occurred within the control Condition (all $p \mathrm{~s}<.210$ ), except for an increase in GMO knowledge ( $p=.008, d=-.30)$. This slight increase may be explained by ambient knowledge gained through other college courses over the five-week period. Another possibility is that exposure to the materials about nutrition triggered participants to read more about foods, including GM foods, over the course of the experiment. Means and within-subjects effect sizes are displayed in Table 5. 
Table 5. Means by condition, effect sizes, and significance values for within-subjects changes of the four dependent variables in Study 4.

\begin{tabular}{lccccc}
\multicolumn{1}{c}{ Variable } & Condition & Week 1 & Week 5 & $\boldsymbol{p}$ & $\begin{array}{c}\text { Cohen's } \boldsymbol{d} \\
\text { Week 1 - Week 5 }\end{array}$ \\
\hline \multirow{2}{*}{ GM Attitudes } & Control & $4.52(1.25)$ & $4.55(1.29)$ & .755 & -.03 \\
& GM & $4.60(1.23)$ & $5.06(1.21)$ & $<.001$ & -.38 \\
GM Risk Perception & Control & $3.64(1.21)$ & $3.52(1.28)$ & .201 & .09 \\
& GM & $3.67(1.21)$ & $3.07(1.28)$ & $<.001$ & .49 \\
GM Knowledge & Control & $4.48(2.30)$ & $5.20(2.41)$ & .008 & -.30 \\
& GM & $4.77(2.69)$ & $6.32(2.36)$ & $<.001$ & -.71 \\
Implicit Attitudes & Control & $-.64(.36)$ & $-.63(.34)$ & .923 & -.03 \\
& GM & $-.59(.42)$ & $-.56(.37)$ & .535 & -.03
\end{tabular}

Note: $N=160$; significance values and Cohen's $d$ refer to within-subjects change, calculated as Week 1 minus Week 5.

Fig. 1. Density Plots Comparing Distributions and Means for Each Condition at Weeks 1 and 5 in Study 4.

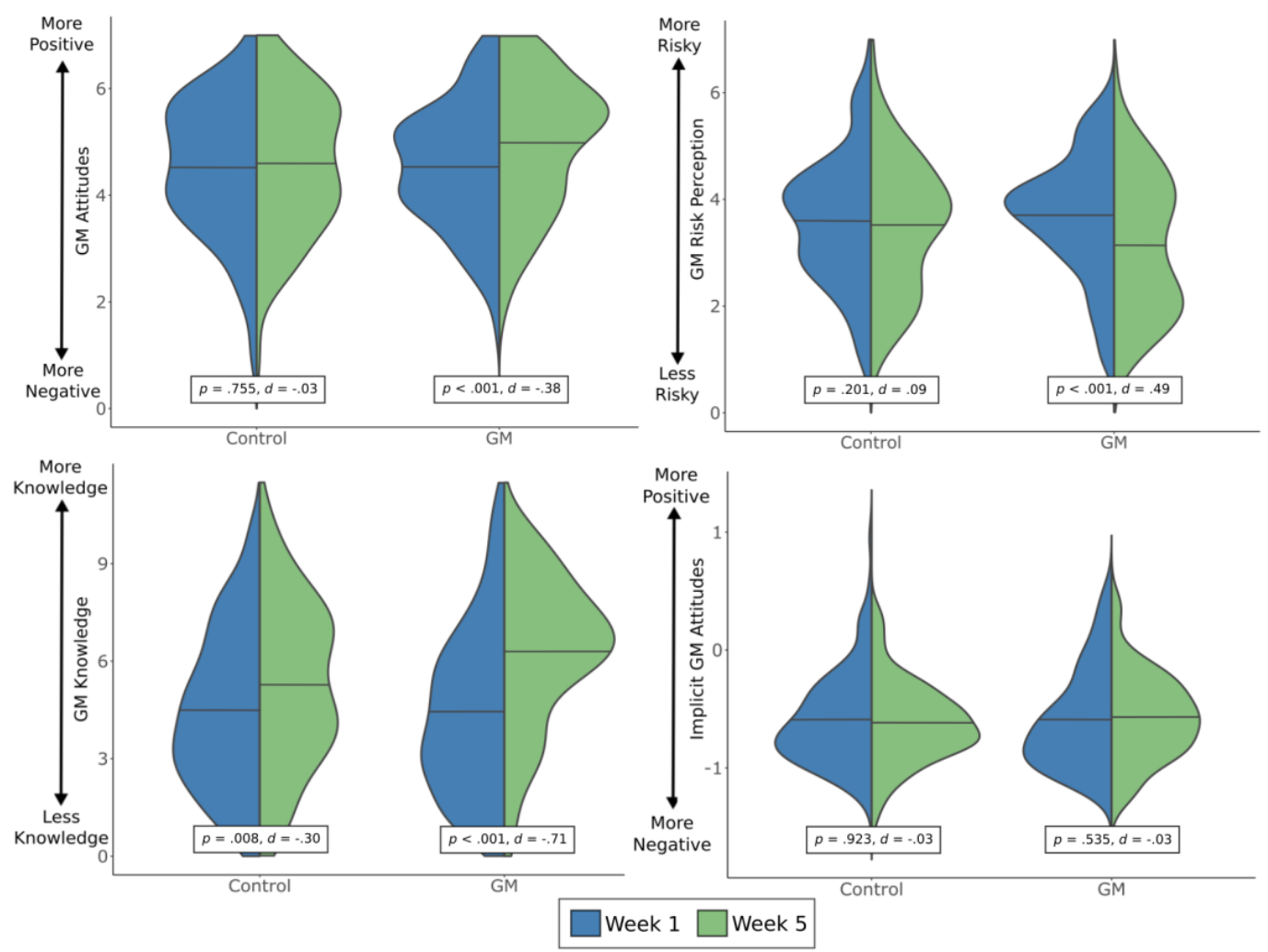

Note: $N=160$; from Week 1 (blue) to Week 5 (green), GM attitudes (top left) and GM knowledge (bottom left) increased and risk perception (top right) decreased for those in the GM condition. Implicit attitudes (bottom right) were unaffected in both conditions. Horizontal lines indicate means for Weeks 1 and 5; the blue half of each plot depicts the distribution for Week 1 and the green half of each plot depicts the distribution for Week 5; significance values and effect sizes (Cohen's $d$ ) refer to within-subject changes from Week 1 to Week 5 for each condition. 
Willingness to eat GM food items also increased over the five weeks for those in the GM condition, as predicted by our second hypothesis. We again analyzed the data using a mixedANOVA, but here the within-subjects change included five time points, one for each GM food item described at the end of each weekly survey. This analysis yielded a significant Week X Condition interaction for willingness to eat a specific GM food item: $F(1,134)=10.08, p=.002$, $\eta^{2} \mathrm{p}=.07$ (Figure 2). The main quadratic effects of Condition and Week were not significant ( $p$ s $>$.45). The two conditions did not differ at Week 1. No within-subjects fluctuation occurred in the GM condition: willingness to eat increased at Week 2 and remained significantly higher at Weeks 3-5, indicating participants were not reacting to specifics about each GM food described. Conversely, those in the control condition were less willing to eat the GM food items compared to those in the GM condition. Indeed, willingness to eat specific GM food items fluctuated widely across Weeks 3-5 $(p \mathrm{~s}<.001)$ in the control condition, suggesting that these participants reacted to idiosyncratic differences in the descriptors of each GM food item (see Table S7 for item descriptions). 
Fig. 2. Depiction of Longitudinal Change in Willingness to Eat GM Food Items for Each Condition in Study 4.

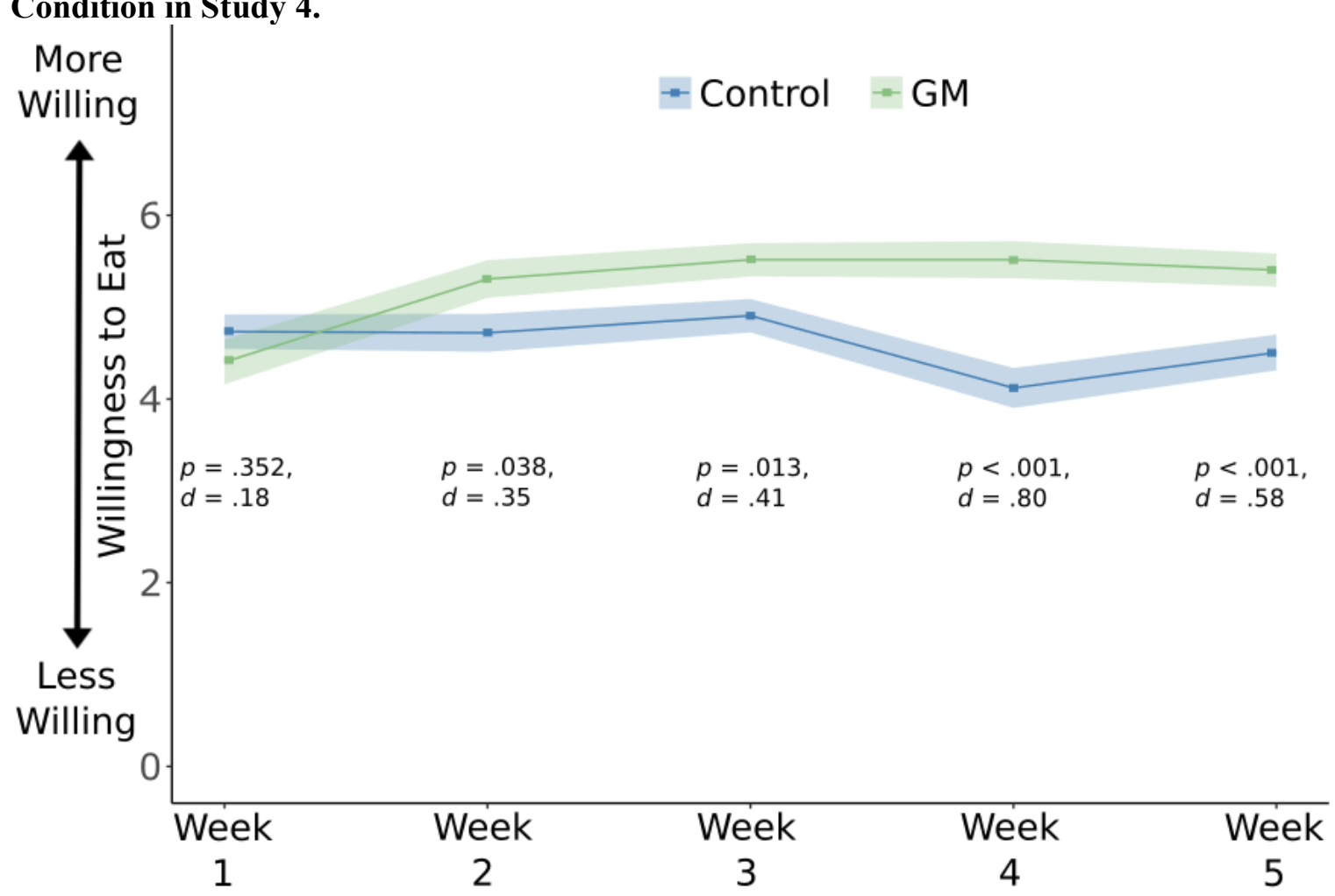

Note: $N=137$; willingness to eat GM foods increased at week 2 and remained greater through week 5 for those in the GM condition (green line); for those in the Control condition (blue line), willingness to eat GM foods remained lower and fluctuated significantly from weeks 3-5.

Significance values and effect sizes (Cohen's $d$ ) refer to comparisons between conditions at each time point; transparent envelope around each line indicates $+/-1 S E$.

\section{Exploratory Analyses}

Following feedback received during peer review, we explored the possibility that the effects of the experimental condition on attitudes might be contingent on specific individual difference variables. Past research suggests that some types of science skepticism (e.g. climate change) may be closely related to ideological variables but that GM foods are more closely related to knowledge (e.g. Rutjens et al., 2018). Further, a recent study reported that those who hold the strongest anti-GM views have the least knowledge (Fernbach et al., 2019). Given these previous findings we thought it important to consider these possibilities here. For example, those 
with stronger preference for natural foods, more negative initial attitudes, or more GM-specific knowledge at Time 1 may have been less affected by the manipulation. Further, we also considered religiosity as a moderator given its occasional associations with GM attitudes in these data.

However, it should be considered that these studies were not designed to test these contingencies (nor did we develop a priori hypotheses). Further, given the subjectivity of the many possible interactions we could test, we limited our exploration to only five interactions on two specific outcomes (GM knowledge and GM attitudes). Key effects are described below and the full models are presented in the supplementary materials (Tables S10-S13).

We first examined whether GM knowledge at Week 1 moderated the effect of condition on knowledge at Week 5 . In a multiple regression analysis, we entered condition $(1=\mathrm{GM}$ condition), Week 1 GM Knowledge (centered), the attention check score, and the Week 1 GM Knowledge $\mathrm{x}$ Condition interaction as predictors of Week 5 GM Knowledge. The interaction was significant, $\beta=-.29, t(174)=3.46, p<.001$. Analyses of simple slopes revealed that the experimental condition was effective in increasing Week 5 GM knowledge for those with lower $(-1 S D)$ Week 1 GM knowledge scores $(\beta=.42, p<.001)$, but not for those with higher $(+1 S D)$ Week 1 GM knowledge scores $(\beta=.01, p=.913)$. Thus, it appears that those with the lowest GM knowledge at the start of the study learned the most over the following three weeks.

We then examined whether GM Attitudes at Week 5 were contingent on GM knowledge, GM attitudes, preference for natural foods, or religiosity as measured at Week 1. Condition did not interact with Week 1 Knowledge $(\beta=-.14, p=.139)$, attitudes $(\beta=-.06, p=.302)$, preference for natural foods $(\beta=.04, p=.686)$, or religiosity $(\beta=.13, p=.224)$. 


\section{General Discussion}

Our data suggest that a lack of domain-specific knowledge about GM technology is a strong and unique predictor of attitudes towards GM foods. Crucially, GM-specific knowledge predicts attitudes towards GM food above and beyond general science knowledge and relevant demographic controls, supporting the hypotheses. Further, the unique predictive value of GM knowledge was in evidence across three countries: the U.S., the U.K., and the Netherlands (Study 3). Finally, results from a longitudinal randomized experiment (Study 4) showed that teaching people about the science behind GM foods leads to more knowledge about and more positive attitudes toward GM, greater willingness to eat GM foods, and to perceiving GM foods as less risky.

Exploratory analyses also suggested that the effects of teaching people about the science of GM technology was not dependent on prior attitudes or knowledge about GM foods, nor was it dependent on individuals' religiosity. Thus, as evident by examining distributions in Figure 1, participants across these individual differences appeared to have experienced attitude change to a similar degree. However, an additional analysis showed that those who had the lowest levels of knowledge at Week 1 also learned the most, suggesting that the content we provided was most effective for those people.

\section{Theoretical Context}

This work provides a relatively simple "mold" for potential campaigns and interventions aimed at increasing GM food acceptance. Our results show that providing members of the public with weekly modules of factual and value-free knowledge results in increased acceptance of GM foods. The survey modules were simple and used freely available videos and infographics. One reason that communicating basic scientific knowledge may be effective in changing attitudes 
towards GM foods is because attitudes around GM foods are not clearly connected to political ideologies in the same way as attitudes in relation to other issues that have received empirical attention, such as climate change skepticism (Rutjens et al., 2018, Drummond \& Fischoff, 2017; Fernbach, Light, Scott, Inbar \& Rozin, 2019).

Implications for the deficit model. Another reason the current approach was more effective than past efforts (e.g. Frewer et al., 1998, 1999) may be because of the way in which the information was communicated. Whereas past research has relied on persuasion models (Petty \& Cacioppo, 1986) and focused on elements such as the number and source of arguments, the present research focused more on how the information was communicated. The information presented in the current study was value-neutral and avoided 'ideological' claims that GM food were safe or good; participants were encouraged to think about the information presented and make their own decisions about GM foods. Thus, this strategy sets the present intervention apart from other studies which focused on persuading participants to accept the benefits and safety of GM products and resulted in more polarized opinions (e.g., Frewer et al., 1998, 2003).

Another reason these studies may be effective is because of the type of information communicated. For example, other research (Ranney \& Clarke, 2016) was successful in changing climate change attitudes through using short videos focused on mechanistic knowledge - that is, knowledge specifically about how climate change works. The authors argue that mechanistic knowledge is special because it provides the foundational information needed to understand the threats posed by climate change. In the present studies, we provided similar information about genes, DNA, and GM procedures; such information is critical to making decisions about why GM technology is safe or risky. 
These points have important implications for the information deficit model of science attitudes which has been criticized for being overly rigid (Brossard and Lewenstein, 2010; Simis, Madde, Cacciatore, \& Yeo, 2016). Several other models of science communication (for reviews, see Brossard \& Lewenstein, 2010; Bucchi, 2008) put emphasis on factors other than simply a lack of information. The integrated model (Longnecker, 2016), for example, suggests that communicating information is important, but emotions, social schemas, and personal or cultural histories all play a role in how one evaluates and uses scientific information.

Our results suggest that communicating information in an engaging and accessible way which prompts perceivers to make their own decisions may be most effective. This is both contrary and complementary to the criticisms of the deficit model. In our view, communicating information in some form or fashion appears to be the key element here, though information should be communicated in a way which allows one the ability to engage with it and time to reflect on it. Of course, this suggestion may be specific to GM foods because GM foods are not overly ideological like climate change, for example (Rutjens, et al., 2018). More research will be needed to explore (and manipulate) these possibilities. Perhaps future investigations relying on the deficit model would benefit by considering different ways to teach people about contentious scientific topics.

Possible applications. One application of this research could be informational campaigns and outreach efforts geared towards communicating domain-specific knowledge instead of combatting nonfactual claims in a defensive fashion. Another application could be a smartphone or social media app which prompts people to read information about a certain topic or technology, presented in manageable modules. Providing the public with domain-specific 
scientific knowledge may facilitate making better and more informed choices about the technology and products to use or avoid.

\section{Limitations and Final Comments}

There are four limitations to consider with the present results. First, aside from Study 3, participants tested in these studies were from convenience samples who resided in the U.S.. Attitudes towards science and scientists differ across countries and cultures (KNAW report, 2013; Rutjens, Heine, Sutton, \& van Harreveld, 2018). Future research should examine these differences in samples more representative of the general populations of nations which differ in their views on scientific findings and their reactions to information communication, more broadly.

Second, there may be other possible reasons that individuals might object to GM foods. For example, learning about the science behind GM technology may be effective in improving attitudes among those who hold intuitive misconceptions about science (Blancke et al, 2015), or about what it means for a food to be considered "natural" (Kronberger, Wagner, \& Nagata, 2014; Rozin, Fischler, Shields-Argel'es, 2009; Scott \& Rozin, 2017). However, such an intervention may work differently when objections are based in emotional disgust or moralized or religious opposition because research has suggested that non-moral issues (e.g. eating meat) can become moralized over time (Feinberg, Kovacheff, Teper \& Inbar, 2019). As such, future research should explore how individuals with these and other existing reactions relevant to scientific knowledge respond when receiving new scientific information.

A third limitation is that our measure of GM knowledge focused on a range of topics related to the science and methodology, as well as regulations, risks, and benefits, of GM products; thus, it was quite broad. We do recommend that future research continue to reconsider 
how GM knowledge is conceptualized and measured. Future research can conduct more specific tests by evaluating these types of quizzes across different populations and by using samples with varying levels of expertise.

A final limitation worth noting is that the Study 4 intervention did not impact implicit attitudes. This may be because implicit attitudes are difficult to access and change or because the task used to measure implicit attitudes did not accurately capture the relevant attitudes. The extent to which changes in implicit attitudes should accompany changes in explicit attitudes has been the subject of debate for decades (e.g., Bargh, 1999; Greenwald, Poehlman, Uhlmann \& Banaji, 2009). For example, people may be aware of their explicit attitudes and override them deliberately, but the implicit attitudes may remain intact.

In conclusion, researchers and scientists may wish to revisit attempts to communicate the science behind their advancements. Rather than combatting claims made by science skeptics and inundating the public with statements about the safety or benefits of their products, perhaps time and money is better invested in basic but targeted education to address the general underlying misconceptions about science. 


\section{Ethics approval:}

All studies were approved or declared exempt by the ethics boards at the respective universities.

\section{Data availability:}

Data and materials are available at the following Open Science Framework link: https://osf.io/4tuhb/?view only=34a9e09f40cf49c3917e346c8391159f

\section{References}

1. Allum, N., Sturgis, P., Tabourazi, D., \& Brunton-Smith, I. (2008). Science knowledge and attitudes across cultures: A meta-analysis. Public understanding of science, 17(1), 35-54.

2. Bak, H. J. (2001). Education and public attitudes toward science: Implications for the "deficit model" of education and support for science and technology. Social Science Quarterly, 82(4), 779-795.

3. Bargh, J. A. (1999). The cognitive monster: The case against the controllability of automatic stereotype effects. In S. Chaiken \& Y. Trope (Eds.), Dual-process Theories in Social Psychology (pp. 361-382). New York, NY: Guilford Press

4. Bastian, B., \& Haslam, N. (2006). Psychological essentialism and stereotype endorsement. Journal of Experimental Social Psychology, 42(2), 228-235.

5. Blancke, S., Van Breusegem, F., De Jaeger, G., Braeckman, J., \& Van Montagu, M. (2015). Fatal attraction: the intuitive appeal of GMO opposition. Trends in plant science, 20(7), 414-418.

6. Brossard, D. and Lewenstein, B. V. (2010). 'A Critical Appraisal of Models of Public Understanding of Science: Using Practice to Inform Theory’. In: Communicating Science; New Agendas in Communication. Ed. by L. Kahlor and P. A. Stout. New York, U.S.A.: 
Routledge, Taylor \& Francis, pp. 11-39.

7. Bucchi, M. (2008). Of deficits, deviations and dialogues: Theories of public communication of science. Handbook of public communication of science and technology, $57-76$.

8. Carpenter, T., Pogacar, R., Pullig, C., Kouril, M., LaBouff, J.,... Chakroff, A. (2018, April 3). Conducting IAT Research within Online Surveys: A Procedure, Validation, and Open Source Tool. http://doi.org/10.17605/OSF.IO/6XDYJ

9. Charles D. 2014. Why the 'non-GMO' label is organic's frenemy. Natl. Public Radio, Washington, DC. https://www.npr.org/sections/thesalt/2014/02/28/283460420/why-the$\underline{\text { non-gmo-label-isorganic-s-frenemy }}$

10. Cuite, C. L., Aquino, H. L., \& Hallman, W. K. (2005). An empirical investigation of the role of knowledge in public opinion about GM food. International Journal of Biotechnology, 7(1-3), 178-194.

11. Dar-Nimrod, I., \& Heine, S. J. (2011). Genetic essentialism: on the deceptive determinism of DNA. Psychological bulletin, 137(5), 800.

12. Devos, Y. et al. (2006) The interplay between societal concerns and the regulatory frame on GM crops in the European Union. Environ. Biosafety Res. 5, 127-149

13. Drummond, C., \& Fischhoff, B. (2017). Individuals with greater science literacy and education have more polarized beliefs on controversial science topics. Proceedings of the National Academy of Sciences, 114(36), 9587-9592.

14. Feinberg, M., Kovacheff, C., Teper, R., \& Inbar, Y. (2019). Understanding the process of moralization: How eating meat becomes a moral issue. Journal of personality and social psychology. 
15. Fernbach, Light, Scott, Inbar, \& Rozin (2019). Extreme opponents of genetically modified foods know the least but think they know the most. Nature Human Behavior.

16. Frewer LJ, Howard C, Shepherd R. 1998. The influence of initial attitudes on responses to communication about genetic engineering in food production. Agric. Hum. Values 15:1530

17. Frewer LJ, Scholderer J, Bredahl L. 2003. Communicating about the risks and benefits of genetically modified foods: the mediating role of trust. Risk Anal. 23:1117-33

18. Frewer, L. J., van der Lans, I. A., Fischer, A. R., Reinders, M. J., Menozzi, D., Zhang, X., ... \& Zimmermann, K. L. (2013). Public perceptions of agri-food applications of genetic modification-a systematic review and meta-analysis. Trends in Food Science \& Technology, 30(2), 142-152.

19. Greenwald, A. G., Nosek, B. A., \& Banaji, M. R. (2003). Understanding and using the implicit association test: I. An improved scoring algorithm. Journal of personality and social psychology, 85(2), 197.

20. Greenwald, A. G., Poehlman, T. A., Uhlmann, E. L., \& Banaji, M. R. (2009). Understanding and using the Implicit Association Test: III. Meta-analysis of predictive validity. Journal of Personality and Social Psychology, 97, 17-41.

21. Hallman WK, Cuite CL, Morin XK. 2013. Public perceptions of labeling genetically modified foods. Work. Pap., Rutgers School Environ. Biol. Sci.

22. Harmon A. 2013. Golden rice: lifesaver? New York Times, Aug. 24. http:/www.nytimes.com/2013/08/25/sunday-review/golden-rice-lifesaver.html

23. Heine, S. J. (2017). DNA is not destiny: The remarkable, completely misunderstood relationship between you and your genes. WW Norton \& Company: New York. 
24. KNAW report (2013). Vertrouwen in wetenschap (Trust in science).

25. Kronberger, N., Wagner, W., \& Nagata, M. (2014). How natural is "more natural"? The role of method, type of transfer, and familiarity for public perceptions of cisgenic and transgenic modification. Science Communication, 36(1), 106-130.

26. Lockie, S., Lyons, K., Lawrence, G., \& Mummery, K. (2002). Eating 'green': motivations behind organic food consumption in Australia. Sociologia ruralis, 42(1), 23-40.

27. Kronberger, N., Wagner, W., \& Nagata, M. (2014). How natural is "more natural"? The role of method, type of transfer, and familiarity for public perceptions of cisgenic and transgenic modification. Science Communication, 36(1), 106-130.

28. Maniaci, M. R., \& Rogge, R. D. (2014). Caring about carelessness: Participant inattention and its effects on research. Journal of Research in Personality, 48, 61-83.

29. Mayer A. 2015. How your food gets the 'non-GMO' label. Natl. Public Radio, Washington, DC. https://www.npr.org/sections/thesalt/2015/01/20/378361539/how-yourfood-gets-the-non-gmo-label

30. Miller JD (1983) Scientific literacy: A conceptual and empirical review. Daedalus 112(2): 29-48. DOI: 10.2307/20024852. Miller JD (1998) The measurement of civic scientific literacy. Public Understanding of Science 7(3): 203-223. DOI: 10.1088/0963$6625 / 7 / 3 / 001$.

31. Miller, J. D. (2011). Longitudinal Study of American Youth, 1987-1994, 2007-2011. [Machine-readable data]. Ann Arbor, MI: Inter-university Consortium for Political and Social Research [distributor].

32. Miller, J. D. (1998). The measurement of civic scientific literacy. Public understanding of science, 7, 203-223. 
33. National Academy of Sciences (2016). Genetically Engineered Crops: Experiences and Prospects. Washington, DC: Natl. Acad. Sci. Eng. Med.

34. Nep S, O'Doherty K. 2013. Understanding public calls for labeling of genetically modified foods: analysis of a public deliberation on genetically modified salmon. Soc. Nat. Resour. 26:506-21

35. Pew Research Center (2016). Major gaps between the public and scientists on key issues. Accessed January 6, 2018 at: www.pewinternet.org

36. Petty, R. E., \& Cacioppo, J. T. (1986). The elaboration likelihood model of persuasion. In Communication and persuasion (pp. 1-24). Springer, New York, NY.

37. Ranney, M. A., \& Clark, D. (2016). Climate change conceptual change: Scientific information can transform attitudes. Topics in Cognitive Science, 8(1), 49-75.

38. Rozin P, Fischler C, Shields-Argel'es C. 2009. Additivity dominance: Additives are more potent and more often lexicalized across languages than are "subtractives.” Judgm. Decis. Mak. 4:475-78

39. Rutjens, B. T., Heine, S. J., Sutton, R. M., \& van Harreveld, F. (2018). Attitudes towards science. In Advances in Experimental Social Psychology (Vol. 57, pp. 125-165). Academic Press.

40. Rutjens, B. T., Sutton, R. M., \& van der Lee, R. (2018). Not all skepticism is equal: Exploring the ideological antecedents of science acceptance and rejection. Personality and Social Psychology Bulletin, 44(3), 384-405.

41. Scott SE, Rozin P. 2017. Are additives unnatural? Generality and mechanisms of additivity dominance. Judgm. Decis. Mak. 12:572-83

42. Shariff, A. F., Cohen, A. B., \& Norenzayan, A. (2008). The devil's advocate: Secular 
arguments diminish both implicit and explicit religious belief. Journal of Cognition and Culture, 8(3), 417-423.

43. Sharma S, Kaur R, Singh A. (2017). Recent advances in CRISPR/Cas mediated genome editing for crop improvement. Plant Biotechnol. Rep. 11:193-207.

44. Simis, M. J., Madden, H., Cacciatore, M. A., \& Yeo, S. K. (2016). The lure of rationality: why does the deficit model persist in science communication?. Public Understanding of Science, 25(4), 400-414.

45. Smith, T. W., Marsden, P., Hout, M., \& Kim, J. (2017). General Social Surveys, 19722014 [machine-readable data file]/Principal Investigator. Sponsored by national science foundation. Chicago: National Opinion Research Center at the University of Chicago [producer and distributor].

46. Spence, A., \& Townsend, E. (2006). Implicit attitudes towards genetically modified (GM) foods: A comparison of context-free and context-dependent evaluations. Appetite, 46(1), $67-74$.

47. Toplak, M. E., West, R. F., \& Stanovich, K. E. (2014). Assessing miserly information processing: An expansion of the Cognitive Reflection Test. Thinking \& Reasoning, 20(2), $147-168$.

48. Wesseler, J. and Zilberman, D. (2014) The economic power of the Golden Rice opposition. Environ. Dev. Econ. 19, 724-742

49. William, G. C., \& Deci, E. L. (1996). Internalization of biopsychosocial values by medical students. Journal of Personality and Social Psychology, 70, 767-779.

50. Wynne, B. (1982). Rationality and ritual: The Windscale inquiry and nuclear decisions in Britain. The British Society for the History of Science: Bucks, England 
